|| ISSN(online): 2589-8698 || ISSN(print): 2589-868X ||

International Journal of Medical and Biomedical Studies

Available Online at www.ijmbs.info

NLM (National Library of Medicine ID: 101738825)

Index Copernicus Value 2019: 79.34

Review Article

Volume 5, Issue 9; September: 2021; Page No.240-256

\title{
REVIEWING THE THERAPEUTIC ACTIVITY OF VITAMIN D WITH ANTIBIOTIC
}

\section{Keerthana.S, Kaushani Sen, Richa Sadhwani, Sakshi Karra}

University of Madras, Chennai, Jadavpur University, Institute of Advanced Research, VIT Vellore

\author{
Article Info: Received 18 July 2021; Accepted 09 September 2021 \\ DOI: https://doi.org/10.32553/ijmbs.v5i9.2220 \\ Corresponding author: Keerthana.S \\ Conflict of interest: No conflict of interest.
}

\begin{abstract}
This article is an examination of the Rar The scientific development and subsequent "Vitamin D and antibodies" continues to influence the researchers all over the globe today. This article examines the research done and published by researchers and scientists. Consideration of current trends and data in scientific queries and demonstrates further aspects of Therapeutic activity of vitamin D with antibiotic. Additionally, this article explores options for vitamin D with cefuroxime. Cefuroxime has been shown to severely impede fracture healing in rats, thus it should be avoided during fracture healing. Vitamin D with Amoxicillin. As it enhancers absorption of many intestinal permeation enhancers, it is very approachable for the pharma sector to invest and develop certain drugs without the fear of toxicity or insufficiency. Vitamin D with azithromycin. vitamin D selectively inhibits inflammatory cytokines, reducing the infiltration of leukocytes, neutrophils, monocytes / macrophages, and mast cells at the site of inflammation. Historical large-scale use and excellent safety record of azithromycin in respiratory infections are reliable. Hydroxychloroquine is a proposed new therapeutic agent in COVID 19 (viral pneumonia).
\end{abstract}

Key words: lyme diseases, intestinal permeation, COVID, inflammatory cytokines, warfarin therapy

\section{INTRODUCTION:}

Vitamin $\mathrm{D}$ is a fat soluble, essential vitamin required by many animals. Amoxicillin is an antibacterial therapeutic drug. Their permeabilities are low. Development of different intestinal permeation enhancers is needed. Many psychiatric disorders are related to Vitamin D deficiency or toxicity. Vitamin D supplementation is proposed to improve clinical symptoms during respiratory tract infections (RTIs). Confluent and reticulated papillomatosis(CARP) is a type of dermatosis caused due to Vitamin D deficiency. Depletion of vitamins is more severe in kwashiorkor than in marasmus. We also discuss how vitamin D levels affected Helicobacter pylori infection and eradication rates. Vitamin D signalling may determine the enterotype of gut microbiota by regulating the intestinal interface as Vitamin D receptor (VDR) is highly expressed here. Vitamin D comes under a group of fat-soluble steroids that are responsible for increasing intestinal absorption of calcium, magnesium, and phosphate and other biological effects as well. In humans, important compounds grouped are vitamin D3 (also called cholecalciferol) and vitamin D2 (ergocalciferol). The originial source of vitamin is synthesis of cholecalciferol in subcutaneous layer of the skin through a chemical reaction that relies on sunlight. Cholecalciferol and ergocalciferol can be taken from diet and supplements. Only a few foods, such as fatty fish, naturally contain large amounts of vitamin D. The conversion of Cholecalciferol to calcifediol (25hydroxycholecalciferol) in the liver; ergocalciferol converted to 25-hydroxy ergocalciferol. The two metabolites of vitamin D (called 25- hydroxyvitamin D or $25(\mathrm{OH}) \mathrm{D}$ ) are measured in serum to determine person\& vitamin D status. Calcidiol is further hydroxylated by the kidneys and some cells of the immune system to form calcitriol (also known as 1,25-dihydroxycholecalciferol), the biologically active form of vitamin D. As a hormone, calcitriol circulates in the blood and its main function is to regulate the concentration of calcium and phosphate and promote healthy growth and remodeling of bones. Calcitriol also has other effects, including some effects on cell growth, neuromuscular and immune function, and reducing inflammation. Vitamin D plays a critical role in calcium homeostasis and metabolism. Its discovery was due to efforts to find dietary substances that children with rickets (infantile osteomalacia) lack. Vitamin D supplements are

used to treat or prevent osteomalacia and rickets. The evidence for other health effects of vitamin D supplementation on the general population is inconsistent. The effect of vitamin D supplementation on mortality is unclear. A meta-analysis found a slight decrease in mortality among the elderly. Another conclusion is that there is no clear reason for recommending vitamin D supplementation to prevent many diseases, and there is no further similarity. Research in these areas requires design.

Many antibiotic classes pose antimicrobial multidrugresistance (MDR) against a plethora of infectious agents including bacterial species as microbes acquire distinct resistance genes. In future, the development of novel antiinfectious intervention strategies including antibiotic- 
independent approaches are need of the hour. Vitamins (vitamin $\mathrm{D}$ and vitamin $\mathrm{D}$ derivates) might be such promising molecular candidates to combat infections caused by bacteria including MDR(multidrug resistant) strains. Non-antifungal drugs act as antifungal agents in various ways toward different targets.

The basic studies of vitamin $\mathrm{D}$ and antibiotic metabolism, the epidemiology of vitamin D levels were done along with that a large number of pre-clinical and clinical research on vitamin $\mathrm{D}$, possible health beneficial characteristics have been published in recent decades. While some studies have found that vitamin $\mathrm{D}$ has beneficial impacts on a range of human bodily systems, others have failed to find that it has health-promoting properties.More and more data indicate that vitamin D supplements may be effective in the treatment and prevention of Covid 19. Furthermore, numerous studies have been published that show the incidence of vitamin D shortage and insufficiency in healthy people as well as subgroups of patients with various disorders. This narrative reviews goal is to provide an overview of vitamin $D$ levels with antibiotic. In addition, we would like to provide an overview of vitamin D and its relevance in cefuroxime, Amoxicillin, cefixime, azithromycin as the role of antibotic in each of them. This review goal or motive is to look into the effects of vitamin D and antibiotics in these area.

\section{MATERIAL AND METHODS:}

The study was conducted using four databases Google Scholars SAGE, DOAJ and PubMed. Selection of papers were done based on keywords and theme relevant to this review. Further the published papers from these databases were arranged in systematic order with respect to year of publication.

\section{RESULTS:}

- Vitamin D with cefuroxime.

- Vitamin D with Amoxicillin.

- Vitamin D with cefixime.

- Vitamin d with azithromycin.

\subsection{Recurrent Sinusitis:}

In this experiment, the highest daily intake of fish oil was 3 $\mathrm{g}$, while the maximum daily dose of multivitamins and minerals was four half-tablets for recurrent sinusitis. Within 2-3 weeks, doses might be increased to an intermediate dosage (providing 7500 IU per day of Vitamin A and 1400 IU per days of Vitamin D). A 9.8-year-old boy had been suffering from recurrent severe sinus infections since he was six years old. For the next 6 weeks, he was given increasing dosages of amoxicillin/clavulanate and amoxicillin/clavulanate ES. They raised his study supplements to the maximum amount throughout this antibiotic treatment; fish oil capsules (provided by his mother) were swapped for cod liver oil, and the family was allowed to restart the immunological formula. After two months in the study, his antibiotic course was completed, his sinus symptoms had resolved, and his sinus symptom score was 0 . He got a cold with a cough and sinus congestion around the end of June 2003, but he didn't need any antibiotics.

In conclusion, the use of flavored cod liver oil and a multivitamin - mineral containing selenium is a low-cost, non-invasive intervention that may be done in an out-patient, community setting as an adjuvant treatment. A trial of supplements before placing an in-dwelling intravenous catheter for IV antibiotics or conducting endoscopic sinus surgery would appear to be acceptable for a kid with chronic/recurrent sinusitis resistant to therapy with oral antibiotics. In the absence of conclusive, big, well-controlled trials, we feel that the exploratory study presents a valuable strategy that physicians may utilize for chosen patients.

\subsection{Relapsing Polychondritis: -}

$\mathrm{RP}$ is an inflammatory disease that affects cartilaginous tissues, primarily the ears, nose, and laryngo tracheobronchial tree. It is severe, episodic, and progressive. The symptoms of RP include auricular chondritis (95-95\% of patients), nasal chondritis (48-72\%) and ocular inflammation with episcleritis, scleritis or retinopathy (50$65 \%$ ). In this case study, A 38-year-old woman with a highgrade fever, sore throat, trouble swallowing, hoarseness of voice, and symptoms of tongue swelling and oral cavity inflammation that resembled Ludwig's angina, needing antibiotic treatment. the patient was put on cefuroxime (750 mg IV t.i.d.) and metronidazole (500 mg IV t.i.d.). The patient's fever had persisted, as had her stridor. A rheumatologist at the hospital identified the woman with polychondritis in her nasal and tracheal cartilages. Tenderness across these places was discovered by the doctor as indications of respiratory tract chondritis and nasal chondritis.

After a three-day pulse of methyl prednisone (250 mg IV daily) and supportive IV hydration, the patient was given steroids in the form of oral prednisone $(1 \mathrm{mg} / \mathrm{kg} /$ day $)$. The calcium and vitamin D supplements were given to her once a week, along with methotrexate (10 mg per mouth). The patient had a remarkable reaction and was entirely symptomfree after five days. On appearance, the patient had obstructive, nonreversible airway disease with a FEV1/FVC ratio of 66 percent, which improved with treatment (ratio becoming 76.6 percent). She was discharged home on the seventh day on a tapering steroid dose (prednisone, $30 \mathrm{mg}$ per day, decreasing by $5 \mathrm{mg}$ per week), but mild tracheal cartilage tenderness and mild pharyngeal erythema remained. The patient's symptoms were completely resolved at a six-week follow-up appointment, and there was no sign of inflammation.

\subsection{Lyme Disease:}

Patients with early Lyme disease, even those who were unaware of any tick bite or rash, may present with one of many clinical presentations that can be categorized as late 
Lyme disease several weeks or even months later. Aseptic meningitis, Bell's palsy, heart block, and arthritis are among them. ELISA tests are generally positive in this situation, but if they aren't, a Western Blot should be done. Antimicrobial medicines other than doxycycline, amoxicillin, cefuroxime, or intravenous ceftriaxone may be required in the treatment of such individuals.

Patients who do not take additional vitamin B do not appear to be deficient in these vitamins, therefore their health is not jeopardized by their lack of supplementation. Vitamin D, on the other hand, should be promoted because it is usually low in individuals with chronic Lyme disease and may assist to reduce inflammation.

\subsection{Postoperative infections in Cardiac Surgical Patients:}

Patients undergoing cardiac surgery are at a higher risk of contracting nosocomial infections. Antibiotic prophylaxis has been shown to have a significant impact on wound infection prevention and is now routine practice in heart surgery. In cardiac surgery patients, the incidence of vitamin D deficiency (circulating 25-hydroxyvitamin D [25OHD] 30 $\mathrm{nmol} / \mathrm{l}$ ) ranges from $15 \%$ to $38 \%$. Vitamin $\mathrm{D}$ has a wide range of impacts, including a critical role in musculoskeletal health and immune system function.

Low $1,25(\mathrm{OH}) 2 \mathrm{D}$ levels were shown to be linked to an elevated risk of a composite of clinically important infections in the research. Patients with circulation 1,25(OH)2D levels over $81.0 \mathrm{pmol} / 1$ had the lowest risk. In the case of circulating 25OHD levels, no such link was discovered. As a result, the findings contradict a systematic review and meta-analysis of observational studies that indicated a substantially higher risk of infection and sepsis in critically ill patients with circulating 25OHD levels $<50 \mathrm{nmol} / \mathrm{l}$. However, the risk ratios for infection and sepsis in the meta-analysis were 1.49 (95 percent CI: $1.12-1.99$ ) and 1.46 (95 percent CI: $1.27-$ 1.68), respectively, which are on average very similar to the non-significantly higher OR we observed in the sensitivity analysis of the study, when compared with adequate 25OHD levels. As a result, the findings do not rule out a greater risk of infection in the presence of inadequate or deficient 25OHD levels.

\subsection{Osteoporotic Patients:}

Osteoporosis is a skeletal illness characterized by decreased bone mass and degradation of bone structure. The most popular procedures for treating various spinal problems, such as degenerative disc disease and spinal fractures, are spinal fixation and fusion surgery. Bisphosphonates limit bone turnover and reduce the risk of bone loss by inhibiting osteoclasts' bone resorption activity. ZA was utilized postoperatively to treat individuals who had lumbar spinal fusion surgery at the hospital in this research. The influence of different bisphosphonates kinds, dosages, route of administration, and duration on spine fusion was unclear.

All patients received prophylactic intravenous cefuroxime for two days following surgery. After the drainage was removed, all patients were able to walk with the use of a lumbar back brace for three months. Within six months, strenuous physical labor and heavy lifting were forbidden, but back muscle strength exercises were recommended. During the follow-up, all patients were given oral calcium $600 \mathrm{mg}$ and vitamin D $800 \mathrm{IU}$ as the foundation of their osteoporosis therapy.

\subsection{Adult Pneumonia Patients:}

Vitamin D is involved in both innate and adaptive immunity, since it aids in the synthesis of antimicrobial peptides. Individuals with vitamin D deficiency and those who got modest regular dosages (daily or weekly) as compared to higher doses showed the highest benefit (monthly or quarterly) Children's randomized controlled trials employing either a single big or small sample size. The clearance of acute clinical characteristics was unaffected by dosages of $7-$ 9 or lower daily doses, and outcomes in avoiding pneumonia recurrence were inconclusive.

In individuals hospitalized with CAP, a single dosage of 200,000 IU vitamin D did not improve outcomes. There was evidence that supplementary vitamin D therapy improved the proportion of patients with full remission of the radiographic symptoms of pneumonia in individuals with low baseline vitamin D levels (25OHD $25 \mathrm{nmol} / \mathrm{L}$ ) and alive at 6 weeks post-study treatment. This is in line with vitamin D's role in the control of the pro-inflammatory response3-5. Given that we were unlikely to be sufficiently powered to adequately analyses our outcome measures, we are presenting our findings with caution.

\subsection{New Findings in the treatment of $\boldsymbol{H}$. pylori:}

\subsubsection{BQT}

For almost three centuries, bismuth has been used to treat syphilis, colitis, and wound infection. The effectiveness of bismuth alone in eliminating $\mathrm{H}$. pylori was 16 to $20 \%$, despite the fact that it is a non-antibiotic. In resistant strains, bismuth add-on triple treatment can enhance effectiveness by 30 percent to 40 percent. BQT had a higher eradication rate than the control group in five studies done in locations with a clarithromycin resistance rate of more than $15 \%$. Because clarithromycin is costly but widely accessible in China, Chen et al evaluated the efficacy and cost-effectiveness of halfdose or standard-dose clarithromycin-containing BQT in Chinese populations. The results showed that the two groups had equal eradication rates. However, as compared to standard-dose clarithromycin-containing BQT, the adverse effects and cost were lower in half-dose clarithromycincontaining BQT. Furthermore, in H. pylori clinical practice in China, high efficacy and safety of different antibiotic combinations in BQT (e.g., amoxicillin and doxycycline or cefuroxime and levofloxacin) were achieved.

\subsubsection{Vitamin therapy}

$\mathrm{Li}$ et al studied the impact of $\mathrm{H}$. pylori therapy and vitamin supplements on the incidence and death of stomach cancer in a blinded randomized placebo-controlled study. The 
researchers discovered that eradicating H. Pylori for two weeks and supplementing with vitamins for 7.3 years might lower the incidence and death of stomach cancer. Vitamins $\mathrm{C}$ and $\mathrm{E}$ have been shown to reduce $\mathrm{H}$. pylori intensity and neutrophilic activity, perhaps protecting against stomach carcinogenesis. $H$. pylori-positive individuals had considerably lower vitamin D levels than those with low levels. Those with high blood vitamin D levels $(10 \mathrm{ng} / \mathrm{mL})$ had greater vitamin D levels than patients with low serum vitamin D levels $(10 \mathrm{ng} / \mathrm{mL})$. To see if adding vitamin $\mathrm{D}$ to the mix will enhance the eradication rate, large-scale prospective research is needed.

\subsection{Patient with Osteomalacia and Coxa-Vara:}

Vitamin D insufficiency is a worldwide issue. One of the most prevalent metabolic bone diseases is dietary deficiencyinduced Osteomalacia. The fracture callus does not develop properly in the presence of Osteomalacia, and healing is sluggish as a result of delayed mineralization. For the previous three years, a 58-year-old obese middle-aged housewife had been experiencing creeping discomfort in her right hip and trouble walking. She travelled to her native town's surgical center for treatment and was diagnosed with a right femoral neck fracture. A more thorough examination indicated Osteomalacia and a vitamin D insufficiency. Her first treatment included reduction and fixation with three cannulated cancellous screws. Her medical treatment began with calcium supplements and vitamin D. Following the recommendation of her local practitioner, she was allowed to begin limited weight bearing with crutches after six weeks and progressed to full weight bearing within three months. Despite the fact that she had been unable to walk without assistance since surgery, her ambulatory condition had deteriorated in two months due to increasing left hip discomfort. She couldn't walk for her regular tasks any more. Fixation and arthroplasty alternatives were reviewed with the patient, and a bilateral THA was scheduled. The objective was to treat the fracture while also correcting the deformity (neck-shaft angle). The anesthetic team and the patient reviewed the options of sequential, simultaneous, or unilateral THA. The patient was a grade 3 American Society of Anesthesiologists patient who was scheduled for a bilateral THA at the same time. Intravenous antibiotic prophylaxis with injectable cefuroxime and prophylactic subcutaneous enoxaparin were among the preoperative medicines. It was a bilateral single-stage complete hip replacement. From the second postoperative day forward, the patient was ambulated with the use of a walker. She was given appropriate dosages of vitamin $\mathrm{D}$ and calcium supplements after surgery. On the sixth day after her surgery, she was released. There were no soft tissue or surgical problems right away.

\subsection{Hospital-Acquired Infections after Hepatobiliary Surgery: -}

Vitamin D receptors are found in macrophages, B and $\mathrm{T}$ lymphocytes, and neutrophils, among other immune system cells. As part of the innate immune response, vitamin D controls the gene expression of antimicrobial peptides. According to certain research conducted in critically sick patients admitted to an intensive care unit (ICU), significant vitamin $\mathrm{D}$ insufficiency before to admission is linked to acute renal damage and death.Vitamin D insufficiency is a worldwide epidemic caused by a combination of lifestyle and dietary variables. Even in Spain, where the weather is thought to aid vitamin D metabolism, investigations have found a paradoxical hypovitaminosis that cannot be remedied by just exposing oneself to sunlight. The optimum vitamin $\mathrm{D}$ serum levels are the topic of a long-running multidisciplinary dispute. A 25-hydroxyvitamin D concentration of less than $50 \mathrm{nmol} / \mathrm{L}$ is the most widely recognized criterion of vitamin $\mathrm{D}$ deficiency, whereas insufficiency is diagnosed at values of $50-75 \mathrm{nmol} / \mathrm{L}$. According to these criteria, more than $90 \%$ of the people in the research were vitamin D deficient.In conclusion, the findings imply that preoperative $25(\mathrm{OH}) \mathrm{D}$ levels in hepatobiliary surgery patients may be a modifiable risk factor for postoperative nosocomial infections. The potential advantages of improving preoperative vitamin D level should be investigated in prospective trials.

\subsection{Fracture Healing in Rats: -}

Non-invasive techniques of measuring the mechanical strength of the cracked callus are not yet adequately established in people, that's why the study was not conducted in humans. Torsion during the wistar rats is the greatest technique to assess the healing of a fracture. Rats were used in this experiment. Cefuroxime was discovered to be ineffective by the researchers. Cefuroxime has never been tested "in vivo" before. As a result, we have no comparable published study to compare the data to. Cefuroxime has long been thought to be safe, and it is now one of the most widely utilized beta lactams in clinical orthopedics. This drug's effects on human osteoblasts when given at low and high doses were studied in a "in vitro" research. Cefuroxime has a potentially hazardous impact on human bone, according to that study, but only at larger dosages. The study found that large dosages of cefuroxime inhibited osteoblast cell growth, metabolism, and calcification activity. Both the mechanical parameters and the histological grade were statistically substantially lower in the cefuroxime group compared to the placebo group, confirming the results of our investigation "in vivo." The doses employed in our study were designed to be similar to those used in clinical settings. Even though the dosage employed in our study was not considered "high," it had a negative effect on bone in vivo. Furthermore, fracture healing is a complicated cellular repair mechanism that involves more than just osteoblasts, which may explain why cefuroxime is harmful to fracture healing in rats at lower dosages.

\subsection{Vitamin D with Antimicrobial properties:}

Vitamin D possess antimicrobial properties against both Gram-positive and Gram-negative bacterial species and is the future of developing drug administration strategies/therapies for curing several bacterial infections. 
Serum vitamin D levels lower in the $H$. pylori positive group $[17.0 \pm 6.9] \mathrm{ng} / \mathrm{mL}$ than in the $H$. pylori negative group $[19.2 \pm 8.0] \mathrm{ng} / \mathrm{mL}$. In $H$. pylori positive group of patients, $\mathrm{H}$. pylori eradication rate in patients with serum vitamin $\mathrm{D}$ levels of $<10 \mathrm{ng} / \mathrm{mL}$ was $71.7 \%$ and $87.3 \%$, in serum vitamin D levels $\geq 10 \mathrm{ng} / \mathrm{mL}$.For a successful eradication of $H$. pylori, a multivariate analysis showed that having serum vitamin $\mathrm{D}$ level $\geq 10 \mathrm{ng} / \mathrm{mL}$ was an independent risk factor having odds ratio $=0.381$ in $95 \%$ confidence interval 0.183 0.791 and $\mathrm{P}=0.010$ ). Randomized controlled trials are needed to find out whether vitamin D supplements may increase the H. pylori eradication. Therefore, Serum vitamin $\mathrm{D}$ level may affect $\mathrm{H}$. pylori infection and its eradication.

\subsection{Effect of H.pylori in lower vitamin D concentration}

Helicobacter pylori was eradicated in $124(77.5 \%)$ patients persisted in $36(22.5 \%)$ patients post treatment(therapy included oral administration of amoxicillin $2000 \mathrm{mg}$ /day). The eradication failure group had a lower mean vitamin D concentration $(15.09 \pm 7.72 \mathrm{ng} / \mathrm{ml})$ than the group with successful eradication $(19.87 \pm 6.35 \mathrm{ng} / \mathrm{ml})$. Eradication failure in individuals with serum vitamin $\mathrm{D}$ deficiency (30 $\mathrm{ng} / \mathrm{ml})$ and individuals with long duration of diabetes ( $\geq 10$ years) had odds of eradication failure of higher as compared to subjects with short duration of diabetes. Lower 25hydroxyvitamin D was associated with $H$. pylori eradication failure and related to dyslipidaemia in T2DM patients. To improve the eradication rate, serum 25 -hydroxyvitamin D must be increased to appropriate levels by activated vitamin D. $18 \%$ of the tested patients had their vitamin D measured. Vitamin D levels are inversely associated with $\mathrm{H}$. pylori infection. Purchase of vitamin D supplements was associated with a negative subsequent $\mathrm{H}$. pylori test. Mean vitamin D levels were moderately higher in those with successful $H$. pylori eradication (19.34 \pm 9.55$)$ as compared to failed $H$. pylori eradication $(18.64 \pm 9.61)$. Only the patients without immunoglobulin substitution responded to the Vitamin D supplementation. Post Vitamin D prescription, the number of antibiotic-free patients increased from 52 to 81 . Hence, new guidelines of administering vitamin $\mathrm{D}$ for patients with insufficient levels of 25-hydroxyvitamin D (less than or equal to $75 \mathrm{nmol} / \mathrm{L}$ ) is developed for their lab. It is established that a Vitamin D/VDR axis has a critical role in optimal expression of defensins and tight junction genes in sustenance with intestinal integrity and also that eubiosis is essential for suppressing NAFLD and metabolic disorders. DEFA5 peptide directly suppresses Helicobacter hepaticus.

\subsection{Toxicity of vitamin $D$ in cats}

A series of cases described concern with the toxicity of Vitamin D in cats caused due to the sole consumption of natural, complementary tinned cat food. Even if marketed as natural and complementary without added Vitamin D, the food leads to hypercalcemia leading to mineralisation of soft tissues. Usually, Serum Phosphate Levels are measured to establish hypercalcemia in cats but it is not always indicative and accurate. Here, the nutritional hypervitaminosis can be a good diagnosis for hypercalcemia in cats. Important takeaways:-

i. relevance of dietary history in diagnosis of hypercalcaemia, and;

ii.measurement of vitamin D metabolites when investigating patients with hypercalcaemia.

\subsection{Positive effect of Amoxicillin}

Amoxicillin is downplayed by cefdinir $\left(3^{\text {rd }}\right.$ generation cephalosporin) which has a lower mortality rate and higher nutritional recovery rate. Antibiotics such as amoxicillin and cefdinir reduced mortality in children with kwashiorkor and marasmoid-kwashiorkor. But, do not reduce mortality in children with marasmus.A patient having a refractory sacral pressure sore healed after starting treatment for small intestinal bacterial overgrowth (SIBO). Here, malnutrition and poor wound healing in patients with chronic pressure sores/wounds is caused due to SIBO. Minocycline, a tetracycline derivative, is most commonly used and inhibits the migration and function of neutrophils. Its antiinflammatory and immunomodulatory effects make it effective for treating CARP. Symptoms - persistent, hyperpigmented, reticulated papules and plaques. Treatments - antibiotics, antifungals, and retinoids. After the treatment with vitamin D psoriasis plaques had flattened with a complete regression of the scaling, and the CRP level reached $73 \mathrm{mg} / \mathrm{L}$ from elevated C-reactive protein (CRP) $346 \mathrm{mg} / \mathrm{L}$. Hence establishing that Calciferol, Calcitriol and Cholecalciferol or other potent forms of calcium are responsible for treatment and recovery from psoriasis apart from the antibiotics used for halting spread of infection. The dynamics of hypocalcemia remediation after clinical reduction in psoriasis is concluded. The existence of drugresistant strains has limited the prospect of conventional antifungal agents. Vitamin D is used as a repurposed drug. Amoxicillin fails to be repurposed due to its virulence eliciting capability.

\subsection{Effect of vitamin D with azithromycin in COVID 19-}

Randomization (independent of calcidiol) achieved a uniform distribution of all research variables between the two control groups. A statistically significant difference in variable hypertension has been determined. Therefore, multiple logistic regression analysis was performed in the ICU ward. The model was adjusted to include the probability of hospitalization as possible interfering variables, such as hypertension units and type 2 diabetes in calcidiol-treated and untreated patients. If CI requires treatment, the dependent variable is in the ICU: $0.300 .03 \mathrm{p}: 0.08$. Of the 26 patients who did not receive calcifediol treatment, $13(50 \%)$ had to be admitted to the ICU, while only 1 of the 50 patients who received calcifediol treatment received intensive treatment. He was sent to the ward and the rest of the patients remained hospitalized. The incidence of hypertension was higher in the control group, although the patients assigned to calcifediol were somewhat older. Depending on the data source, the age is slightly different, but most patients are in 
the 50-74 year range. Among the most widely prescribed drugs, the consistently displayed group of anatomical therapeutic chemistry includes anti-infectives for systemic use, therapeutics for the blood and hematopoietic organs, and therapeutics for the cardiovascular and musculoskeletal systems. Commonly used adjuvant treatments include antithrombotic drugs, corticosteroids, antibiotics, metformin, vitamin supplements (C and D) for blood clotting, $\mathrm{H} 2$ receptor antagonists, and interleukin inhibitors. Hydroxychloroquine is the most widely used drug. All repeated medications are related to the increase in medication use during hospitalization. Compared with prehospital, dexamethasone, corticosteroids, azithromycin and toshirimabu are also used during hospitalization. Oxygen saturation ( $\mathrm{SpO} 2)$ and oxygen index $(\mathrm{SpO} 2 / \mathrm{FiO} 2)$ showed a small but significant increase in the combination group, while a decrease was observed in the control group. Compared with the control group, bilateral pneumonia was more common in the combined group. After treatment, the plasma ferritin of patients in the combined pneumonia group was significantly reduced, but there was no difference in Ddimer. 4.444 billion people worldwide were infected with SARSCoV2, resulting in critical deaths, but there is no specific treatment or vaccine available for COVID19. By using ACE2 as a cell entry receptor, SARSCoV2 enters respiratory epithelial cells and initiates replication, increasing viral load. The damaged cells trigger an inflammatory response, which is interpreted as the clinical signs and symptoms of COVID19 patients. The combination of magnesium supplements and vitamins has been shown to have a beneficial effect on patients with COVID19. Magnesium-related benefits may be achieved by 1) enhancing vitamin D activity and 2) enhancing immune response. Zinc is also necessary for proper absorption of certain vitamins. Zinc deficiency has been shown to increase the risk of infection or degenerative diseases. Clinical trials using zinc in other parts of the world have determined the exact role of zinc in the COVID19 pandemic. Hydroxychloroquine, nitazoxanide, and ivermectin have similar baseline levels of impaired daily living functions, and generally have similar improvement rates to non-AA users. Vitamin D deficiency is not only considered a potential risk factor for Covid19 patients, but it is also frequently reported in these underlying diseases. Vitamin D deficiency can be considered as one of the reasons behind many of these potential complications, including Covid19. Several reports emphasized that lack of vitamin D can lead to high blood pressure, diabetes, cancer and cardiovascular disease, especially in the elderly. The relationship between race and Covid 19 was identified in the priorities of the emergency public health investigation. Recent reports indicate that black patients have a higher mortality rate than white patients with Covid19. Lymphopenia and T-cell dysfunction also reportedly play a role in the development of the disease. In view of the possible beneficial effects, vitamin D selectively inhibits inflammatory cytokines, reducing the infiltration of leukocytes, neutrophils, monocytes / macrophages, and mast cells at the site of inflammation. Historical large-scale use and excellent safety record of azithromycin in respiratory infections are reliable. Hydroxychloroquine is a proposed new therapeutic agent in COVID 19 (viral pneumonia).

\subsection{Effect of vitamin D with azithromycin in Chronic obstructive pulmonary disease (COPD) -}

The main result is the time of the first deterioration. Secondary outcomes observed worsening rates, time from first admission, time to second worsening, FEV1, standard of living, and morbidity. Compared with the placebo group, the mean serum $25(\mathrm{OH}) \mathrm{D}$ level of the vitamin D group was significantly increased (mean difference between the groups, $30 \mathrm{ng} / \mathrm{ml}[95 \% \mathrm{CI}, 2733 \mathrm{ng} / \mathrm{ml}] ; \mathrm{P}<0.001)$. Median time to first deterioration (hazard ratio, 1.1 [CI, 0.82 to 1.56$], \mathrm{p}=$ 0.41 ), deterioration rate, FEV1, hospitalization, quality of Life and mortality did not differ significantly between the groups. is the same. However, a post-hoc analysis of 30 participants with severe vitamin D deficiency (serum 25 $[\mathrm{OH}] \mathrm{D}$ level $<10 \mathrm{ng} / \mathrm{ml}$ ) from baseline showed that the deterioration of the vitamin $\mathrm{D}$ group was significantly reduced. There is no significant relationship between clinical site and the $25(\mathrm{OH}) \mathrm{D}$ level (analysis of variance, $\mathrm{P}=0.254$ ). Low levels of $25(\mathrm{OH}) \mathrm{D}$ are related to poor initial health. These 973 members used 4,415 AECOPD during the year. During the year, a total of 360 people (37\%) still had AECOPD without worries. Patients with the largest $25(\mathrm{OH})$ D layer have the shortest time to the first AECOPD, but this change has not reached statistical understanding. There is no evidence that data exchange between baseline $25(\mathrm{OH}) \mathrm{D}$ levels at randomized treatment allocation (azithromycin versus placebo) can be used as a predictor of time to first deterioration or rate of deterioration at 1 year. The main objective of is to test the efficacy of azithromycin on the basis of standardized maximum treatment in the acute treatment of central batches of COPD requiring hospitalization. The secondary objective is to demonstrate safety by reducing the dose and duration of permanent treatment during and after ESA without loss of efficacy The patient has a very profound inactive dynamic of COPD and without recurrence of physical activity (FA) associated with the AES. All details are available in the statistical analysis plan and are completed prior to interim analysis. Local researchers and their specialized clinical students compiled the data into an electronic case report, which was monitored by the research coordinator. Surface density (3D measurement of Lm, measurement of emphysema) is measured based on $\mu \mathrm{CT}$ to confirm that the nuclei used for expression analysis are truly representative samples. Compared with unused donor lung nuclei, COPD lung nuclei have a lower surface density ( $p<0.0001)$. Compared with unused donor lung nuclei, COPD lung nuclei have a lower density $(\mathrm{p}<0.0001)$. Compared with unused donor lung nuclei, the total prayer volume of COPD lung nuclei is significantly reduced. CYP27B1 expression and localization in lung tissue $=0.97)$ and protein level $(\mathrm{p}=0.40)$ Immunohistochemical staining of epithelial cells, submucosal glands and immune cells was positive for CYP24A1. ). Compared to CYP27B1, endothelial cells stain 
ineffectively as enzyme positive and highly stained. Sometimes a small number of immune cells stained positively, but the staining was weak.

\subsection{Effect of vitamin D with azithromycin in Asthma -}

The goal of asthma treatment is to minimize the burden of symptoms, prevent seizures, and (if possible) reduce the risk and impact of progressive pathophysiology and adverse outcomes. The author describes the administration. The best use of short-acting $\beta 2$ agonists and long-acting muscarinic antagonists (Ciotoropium). These uses also describe relatively new uses of pediatric allergen-specific immunotherapy, bio-monoclonal antibody therapy, the use of the azarad antibiotic azithromycin, and vitamin D. Control of laminar flow devices, and the application of symptoms may actually be attributed to cases of respiratory dysfunction other than asthma. FeNO measurement can be used for the diagnosis and treatment of asthma in children and adolescents. In short, asthma is sometimes difficult to recognize, and FeNO can help. It is important to realize that inhaled $\beta 2$-agonist bronchodilators, no matter how they are administered, can exacerbate hypoxemia in asthma patients. Hypoxemia can be fatal, and pulse oximeters are recommended, especially in primary care settings. They are cheap and easy to buy, suitable for probes of all ages. In a preliminary study, we demonstrated the advantages of highflow nasal catheter oxygen therapy over mask endoplasmic reticulum oxygen therapy. They are safe and effective. The pulmonary score and hypoxemia are used to measure the reduction of dyspnea in the first 2 hours of treatment. More research is needed in this area. Prednisolone is often used to treat acute asthma. In clinical trials, tiotropium bromide, when used in conjunction with adjunctive therapy with ICS (inhaled corticosteroid), was found to improve lung function in patients with poorly regulated asthma. Tiotropium bromide is particularly useful for patients with or without LABA (long-acting beta agonist), and for moderate or high asthma with ICS with inadequate control, it may be a new additional treatment option. A recent meta-analysis of patients with moderate to mild asthma showed that vitamin D may reduce the risk of severe asthma attacks and medical use.

\subsection{Effect of vitamin D with azithromycin in Acne vulgaris -}

The study included 120 subjects, 1637 years old, of whom 38 were men and 82 were women. There were no statistically significant differences between treatment groups, depending on age, key points, body weight, and the number of early treatment lesions on the face. Of the 120 subjects, subjects were recruited and 93 of them completed the study. All subjects receiving one or more doses of azithromycin were evaluated for safety. A total of 27 adverse events were recorded in 21 subjects. The majority of adverse events included laboratory findings, namely elevated liver enzymes and gastrointestinal side effects. It is unexpected that none of the previously reported adverse events reported to have been reported to .7 subjects withdrew from all studies and fully recovered.

\subsection{Effect of vitamin D with azithromycin in Cystic fibrosis -}

Treatment of CF cells with $107 \mathrm{M}$ vitamin D reduced virus replication by -fold, while virus replication was treated with $109 \mathrm{M}$ or $108 \mathrm{M}$. Even if it is not suppression. The reduction in virus replication is not due to vitamin D destroying cells. Recently, it was reported that the IFN pathway can be organized by vitamin D interdependently and activate the TLR pathway at the same time. To confirm that the IFN pathway does not participate in the antiviral activity of vitamin D in CF cells, we studied in depth the explanation of the pattern recognition receptor (PRR) TLR3, RIGI and MDA5 in vitamin D drugs. in RV-infected patients. CF cells. However, compared to untreated cells, vitamin D in infected CF cells amplified the expression of LL37 in a dosedependent manner, up to 17.4 times more than was induced by vitamin D 10-7 M. Replication of RV was significantly reduced in -treated CF cells. Compared to untreated cells, LL37 found a significant negative correlation between RV charge and LL37 levels. Study population included CF patients and 41 control groups. The average intake of (kcal / $\mathrm{kg}$ ) and the ratio of carbohydrates to highly unsaturated fats were significantly higher in subjects with $\mathrm{CF}$, but the value of monounsaturated fat (percentage) was in Natotuda. Significantly higher levels of interleukin 6 (Il6), tumor necrosis $\alpha$ (TNF $\alpha$ ), C-reactive protein (RCP), CAT activity, TBARS were observed in the group of CF, SOD, vitamin D and vitamin $\mathrm{A}$ and isoprostaglandins. Compared with untreated patients, the rate of homozygous, meconium ileum and chronic F508del colony formation in the macrolide antibiotic treatment group was significantly increased. Significant differences were determined by sweat test, the rosette test for the number of acute attacks and spirometry. The only significant difference found between the oxidation parameters and inflammation parameters was the level of $\mathrm{TNF} \alpha$ (lower in the group that received AZM.

\subsection{Effect on Respitary tract infection and Covid-19}

The publish marketing surveillance study was once a nonrandomized, open, non-comparative, multi centric and the drug CO2 pill (Fixed dose mixture of Cefixime $200 \mathrm{mg}$ and Ofloxacin $200 \mathrm{mg}$, Medley Pharmaceuticals Ltd. Mumbai) was once administered to patients struggling from respiratory tract infection for duration of 7-14 days. Informed consent was obtained from the sufferers and the post advertising surveillance used to be in accordance with the clinical concepts laid down in statement of Helsinki 279 subjects were monitored across India. Based on the above findings, we conclude that vitamin D3 supplementation given as a single oral dose of 100,000 IU to children under-five years of age admitted to hospital with ALRI did not alter either the course of the disease in terms of decreased durationof hospital stay, decreased time for defervescence, decreased complications, decreased need for ICU stay or decreased mortality or recurrence of ALRI 
within 90 days of discharge. This dose of vitamin D3 administered orally was effective in raising the serum levels of $25(\mathrm{OH}) \mathrm{D}$ levels within 72 hours of administration without producing any clinical evidence of toxicity.

When considering the risk to benefit ratio of a treatment, when the potential benefits of a treatment significantly outweigh the risks, then recommending a treatment during a pandemic like we are currently experiencing with so many lives at risk seems warranted. The risk of remaining vitamin $\mathrm{D}$ deficient and being unable to mount an effective antimicrobial peptide response proven to be regulated by vitamin $\mathrm{D}$, far outweighs the risk of possibly developing toxicity related to hypercalcemia caused by excessive vitamin D intake. This is especially true when hypercalcemia caused by excessive vitamin D intake has consistently been shown to be reversible with cessation of vitamin $\mathrm{D}$ intake without any long-term sequelae. The development of hypercalcemia can also be easily monitored and prevented by periodic blood tests measuring serum calcium, 25(OH)D and intact parathyroid hormone concentrations. Studies suggest that this untoward effect will not likely occur after taking 10,000 (250 mcg) IU/day for extended periods of time. Vitamin D deficiency is a significant risk factor for the development of acute respiratory tract infections, as well as many other diseases. While vitamin D may not ultimately prove to be active against coronavirus, the resulted augmented host defense generated will be active against a number of other microorganisms that may potentially cause deadly opportunistic infections as a result of the Coronavirus infection. The daily intake and amount of vitamin D required in the blood to support sustained AMP production against infectious microorganisms is currently unknown but is likely to be in the range of $10,000(250 \mathrm{mcg}) \mathrm{IU} / \mathrm{day}$ to $25,000(625 \mathrm{mcg}) \mathrm{IU} /$ day. The literature does not support hazards but instead significant advantages if the population could rapidly achieve and maintain robust serum $25(\mathrm{OH}) \mathrm{D}$ concentrations. It is known that the body generates $10,000(250 \mathrm{mcg}) \mathrm{IU} /$ day to $25,000(625 \mathrm{mcg}) \mathrm{IU} /$ day of vitamin $\mathrm{D}$ in the photosynthetic response to sunshine without causing hypercalcemia, while effectively treating tuberculosis infections, rickets and psoriasis plaques. Studies including our own extensive clinical experience over the past 11 years indicate these doses to be well-tolerated and safe, as well as inexpensive.

\subsection{Effect of vitamin D supplements:}

People who were randomly assigned 60,000 IU cholecalciferol had no significant $28 \%$ lower risk of having antibiotics prescribed at least once than did people in the placebo group (RR: $0.72 ; 95 \%$ CI: $0.48,1.07$ ). In analyses stratified by age, in subjects aged $\geq 70 \mathrm{y}$, there was a significant reduction in antibiotic use in the high-dose vitamin D compared with placebo groups (RR: 0.53 ; 95\% CI: $0.32,0.90)$, whereas there was no effect in participants aged $<70$ y (RR: $1.07 ; 95 \%$ CI: 0.58, 1.97) (P-interaction $=0.1)$. In this method 277 patients or sufferers with insufficiency was being supplemented with vitamin D3, 1500-1600 IU/day for 12 months. Each patient used to be its personal control and statistics on antibiotic consumption used to be monitored 12 months before and 12 months after initiation of vitamin D3 supplementation. It was seen that Vitamin D3 supplementation resulted in a significantly reduced antibiotic consumption, from 20 to 15 days/patient $(p<0.05)$. The number of antibiotic-free patients increased from 52 to 81 after vitamin D3 supplementation; OR $1.79 ; 95 \%$ CI $1.20-2.66(p<0.01)$. The number of antibiotic-prescriptions decreased significantly, a finding that mainly was attributed to a reduction of respiratory tract antibiotics $(p<0.05)$. Subgroup analysis showed that only patients without immunoglobulin substitution $(n=135)$ had a significant effect of vitamin D supplementation.

\subsection{Antibacterial properties}

Out of 43 clinical isolates ;28 were Gram-negative , K.pneumoniae was the predominant organism solates ; followed by E.coli(8)then Ps.aeruginosa. Gram -positive isolates were 17 distributed as ; 9 isolates belonged to S. aureus while 5 for Strep.pneumoniae and 2 for Strep.pyogenes Antibiotic Sensitivity: Twelve different antibiotic discs were used : levofloxacin $5 \mu \mathrm{g}$, ciprofloxacin $10 \mu \mathrm{g}$, cefotaxime $30 \mu \mathrm{g}$, amoxicillinclavulan acid $30 \mu \mathrm{g}$, imipenem $10 \mu \mathrm{g}$, aztreonam $30 \mu \mathrm{g}$, meropenem $10 \mu \mathrm{g}$, azithromycin $15 \mu \mathrm{g}$, chloramphenicol $30 \mu \mathrm{g}$, nitrofurantoin $30 \mu \mathrm{g}$, rifampicin $15 \mu \mathrm{g}$, vancomycin $10 \mu \mathrm{g}$. Bactrial resistance is one of the major causes of failure in the treatment of infectious diseases resulting in increased morbidity, it was observed from the present study that clinical bacterial isolates which were tested have showed high resistant to conventional antibiotics. E. coli was sensitive to levofloxacin and ciprofloxacin and nitrofurantoin. K. pneumoniae was sensitive to ciprofloxacin, levofloxacin, chloramphenicol and imipenem,Ps.aeruginosa was sensitive to ciprofloxacin and meropenem whileS. aureus was sensitive to rifampicin, levofloxacin, and vancomycin. These results were compatible with other studies that tested antibacterial sensitivity towards $\mathrm{Gr}+\&$ Gr-isolates; rifampicin, levofloxacin \& vancomycin were the most effective antibacterial agents against $\mathrm{Gr}+$ bacterial isolates in our study whereas ciprofloxacin \& levofloxacin were the most effective towards Gr-isolates. Six bacterial isolates have been chosen to detect the vitaminefficacy ; SaS, StpS , $\mathrm{EcU}, \mathrm{AbB}, \mathrm{KpS}, \mathrm{PsB}$ which represent highly multi-drug resistant isolates; S.aureus(sputum), Strep. pneumoniae (sputum), E.coli (urine), A.baumannii (blood), K.pneumoniae (sputum), Ps.aeruginosa (blood) respectively.The results clearly show he ability of vitamin D3 to inhibits the bacterial growth of both $\mathrm{Gr}+\& \mathrm{Gr}-$ isolates, the third concentration $90,000 \mathrm{IU} / \mathrm{mL}$ was the most effective one particularly towards SaS \& StpS because of the large inhibition zone that result $(29,26 \mathrm{~mm})$ respectively, whereas $70,000 \mathrm{IU} / \mathrm{mL}$ caused less inhibition zone $(22 \mathrm{~mm})$ with StpS isolate ,the bacterial suspension was in conc.of $\left(10^{10} \mathrm{CFU} / \mathrm{mL}\right)$. Small inhibition zone 
was reported after treatment $\mathrm{KpS}$ with the first and second vit.concentrations, those caused $(7,10 \mathrm{~mm})$ while $\mathrm{EcU}$ has been showed $(10 \mathrm{~mm})$ with $50000 \mathrm{IU} / \mathrm{mL}$ Supplementary studies may be required to establish vitamin D antibacterial activity and the possible mechanisms by which vitamin D may have a therapeutic role in managing a variety of infections particularly against pathogenic bacteria and development of potential therapeutic applications.

\subsection{Effect of cefixime in the warfarin therapy}

The potential find out about was carried out in Pakistan between 2017-2019 in the settings of Armed Forces Institute of Cardiology and National Institute of Heart Diseases (AFIC/NIHD) Rawalpindi, in post-operative surgical wards and surgical OPD. All topics gave their knowledgeable consent for inclusion earlier than they participated in the study. The find out about was once conducted in accordance with the Declaration of Helsinki and the protocol that was authorized with the aid of the ethical committee of cardiac health facility AFIC/NIHD as per AFIC-IERB-SOP-15 (reference no. 22/11/R\&D/2018/04). Appropriate pattern sizes had been taken in a defined duration of find out about using nonprobability consecutive sampling technique. Postoperative sufferers of both genders $(20-65$ years $)$ with mitral valve replacement (MVR), double valve replacement (DVR), and aortic valve replacement (AVR)

to various valvular illnesses discharged due warfarin therapy have been chosen for study. Patients with serum creatinine stages that are greater than ordinary i.e., $>1.2 \mathrm{mg} / \mathrm{dL}$ or with alanine aminotransferase (ALT) ranges $>41 \quad \mathrm{U} / \mathrm{L}$ which may additionally make a contribution to an extend in INR levels, patients receiving complex regimens including drugs that have major interaction with warfarin, as properly as febrile sufferers with suspicion of infection, had been excluded from the study. Also they were now not accepted to use any other over-the-counter concomitant pills within 7 days of the first dose of warfarin and for the duration of the lookup and have been now not permitted to consume alcohol, grapefruit, caffeine, licorice, quinine, or cranberry-containing ingredients or drinks during the research till after the outpatient visit on day 7. Eight patients whose INR values had been not reachable at the time of discharge had been removed from the study. The last seventy five patients had been placed in three organizations based totally on antibiotics prescribed after valve substitute surgery. All 75 sufferers discharged with warfarin obtained preferred $5 \mathrm{mg}$ dosages. Group A sufferers on warfarin remedy after mechanical valve replacement receiving quinolone such as moxifloxacin whilst group B sufferers on

warfarin remedy acquired levofloxacin Group $\mathrm{C}$ individuals on warfarin therapy were now not receiving quinolones but receiving any other antibiotic, i.e., cefixime. A documented therapeutic INR earlier than the start of quinolones and cefixime at the time of discharge and a documented INR inside 7 days after it has been began was once recorded and results have been in contrast by

Wayof potential ofSPSSanalysis, following records were co mpiled through scientific workstation session and clinical re cord review, such as demographic information (age, gender), concomitant medications, poisonous habits such as smoking and alcohol, as nicely as the analytical parameters worried such as creatinine, albumin.

\subsection{Properties and therapeutic application of vitamin D}

The study was done to find about the sources of Vitamin, the diseases that can occur due to its efficiency and it's deficiency also results in abnormalities in calcium, phosphorus, and bone metabolism. VDD causes a decrease in the absorption of dietary calcium and phosphorus, resulting in an increase in PTH levels, physiological actions of vitamin D. It also mentions about the disease that may occur like Hypertensions, Heart Diseases, Parkinson's Disease, Obesity, Fractures and Falls, Cognitive impairment, Influenza etc.

\subsection{Effective of synergistic strategy}

Evolution and adaptation apply to all the living forms on the earth. Microorganisms also adapt to the changing environment. The continued use of one kind of drug leads to MDR evolution in pathogens. As a result, higher doses of antibiotics are required that cause toxicity effects. Combinatorial effect and multiple size/shape and charges of nanoparticles do not allow the resistance development in the pathogen. Thus, generalized resistance could not be developed or acquired by pathogens. The smaller nanoparticles exert more significant antimicrobial activity due to their easy diffusion in the pathogen's cell membrane.The synergistic application enhances the efficiency of antibiotics towards the pathogens in a cooperative manner. The reduction in the dose of antimicrobial and low concentration of nanoparticles reduces the toxic effect on human cells and increases antimicrobial properties report a synergistic effect of the combination of antibiotics with the silver NPs. This mixture of antibiotics and nanoparticles was highly effective against multiple drugresistant bacteria. In synergism, the nanoparticles are surrounded by the antibiotics molecules; hence, the antibiotic concentration would be higher at the target site. The chelation effect of nanoparticles followed by antimicrobial effects leads to increased destruction of bacteria. found that silver NPs, along with antibiotics like ceftriaxone and ofloxacin, enhances its efficacy significantly towards S. typhi, S. para typhi, and several Gram positives and Gramnegative microbes. proved the hypothesis that AgNPs along with various antibiotics could be used to kill multiple pathogenic microbes, including Salmonella typhimurium. They claimed good antibacterial effect of a combination of AgNps with antibiotics. We also observed 
similar results in our experiment that antibiotics or nanoparticles gave a lesser zone of inhibition compared to the combination. The nanoparticles significantly restricted bacterial growth. found that the potency of less effective antibiotics such as tetracyclin or neomycin against multidrug-resistant Salmonella typhimurium DT104could is improved after combining with nanoparticles. Results of the present study also suggest that $16.90 \mu \mathrm{g} \mathrm{AgNps}$ along with $50 \mu \mathrm{g} / \mathrm{ml}$ of cefixime exerts potent antibacterial activity.

\section{Discussion}

- Vitamin D with cefuroxime.

- Vitamin D with Amoxicillin.

- Vitamin D with cefixime.

- Vitamin d with azithromycin.

\subsection{VDP Ligands:}

$1,25(\mathrm{OH}) 2 \mathrm{D} 3$ can have an influence on almost all human illnesses, particularly in terms of prevention. However, when VDR ligands are overdosed or administered to human beings with an incorrect genetic profile, this comprehensive understanding comes with a caution about potential adverse consequences. Personalized medicine, like all other substances with therapeutic potential, will become increasingly essential. In this regard, the VDR and its ligands have a distinct advantage as therapeutic medicines of the twenty-first century because of their deep molecular knowledge of their effects, both at the receptor-ligand level and at the genome-wide level.

\subsection{Disease causes due to vitamin $D$ deficiency:}

Vitamin D deficiency is linked to a higher risk of pneumonia, more severe illness, and poorer outcomes. The pattern is consistent with preventive studies, which demonstrate that people with vitamin D deficiency benefit the most. Low vitamin D levels have also been linked to a greater risk of pneumonia, a more severe illness, and poor outcomes in observational studies. In the case of $H$. pylori, susceptibilityguided therapy is thought to have a high success rate, the therapeutic decision should be based on the availability of susceptibility testing and the efficacy of local empiric therapy. The impact of probiotics might be strain-specific, and additional research into the dosage and frequency of vitamins in eradication regimens is needed. On the other hand, Cefuroxime has been shown to severely impede fracture healing in rats, thus it should be avoided during fracture healing. If these findings are replicated in people, cefuroxime treatment during bone healing should be avoided. We may infer from the findings that Vitamin D supplementation with cefuroxime is effective in many situations. Antibiotics combined with Vitamin D supplements can help individuals with recurrent sinusitis, relapsing polychondritis, Lyme disease, Osteomalacia, Coxa-Vara, and Osteoporosis.

\subsection{Effect of vitamin D supplementation with Cefuroxime:}

Use of Vitamin D is done for bone health in order to regulate phosphate and calcium metabolism. And it is well established fact that the vitamin D deficiency is allied with an augmented risk of cardiovascular disease, diabetes, hypercholesterolemia, and COVID-19. So, Vitamin D is used as a repurposed drug. Many antibacterial drugs have broad-spectrum antifungal activity as they are commonly used to decrease extracellular glycan level and cell surface hydrophobicity, for gene expression regulate levels of adhesion, hypha, or biofilm formation, and lastly, to inhibit efflux pump activity. But, $\beta$-lactam antibiotics are unable to inhibit the growth of Candida species, and amoxicillin can increase the virulence of Candida species. in Caenorhabditis elegans. Helicobacter pylori is a gram-negative bacterium which colonizes the human gastric mucosa. H. pylori infection is associated with chronic gastritis, peptic ulcer disease, MALT lymphoma, and gastric cancer. And the presence of Helicobacter pylori indicates the presence of Vitamin D deficiency. Data collection of one month followed by $\mathrm{H}$. pylori infection tests (using urea breath or stool antigen tests) were conducted. A negative $\mathrm{H}$. pylori test following a positive result implied eradication. Multivariate regression models helped to assess associations between $\mathrm{H}$. pylori infection, eradication, and levels of vitamin D. Systemic inflammation blocks insulin signalling pathways and leads to insulin resistance and glucose intolerance. They are the driving force for hepatic steatosis. High-fat-diet feeding (HFD) is necessary along with additional vitamin D deficiency (VDD) is needed, to induce strong insulin resistance and fatty liver. Helicobacter hepaticus, a murine hepatic-pathogen, is substantially amplified in the ileum, whereas Akkermansia muciniphila, a helpful symbiont, is diminished under Vitamin D deficit diet. Solution to invert this is oral administration of DEFA5. Before the treatment of amoxicillin with clavulanic acid at 2:1 ratio, the colony forming units(CFUs) were three times greater than after the treatment $-0.96 \times 10^{7} \mathrm{CFUs}$. Indicating that amoxicillin and clavulanic acid aid in invitro inhibition of Helicobacter hepaticus by DEFA5.14 years post trauma, a 66-year-old woman reported sacral sores. She was diagnosed with osteomalacia due to vitamin D deficiency. In spite of oral supplementation, serum levels of calcium, phosphorous, and vitamin D remained low. But gastric and duodenal fluid testing resulted in E. coli, Streptococcus species, and Neisseria species and E. coli, Candida glabrata infection respectively. the patient was prescribed polymyxin $B$ sulfate and amphotericin B to overcome this SIBO infection. After this, serum levels of calcium, phosphorous, vitamin D, and other fat-soluble vitamins gradually increased for this patient.Severe acute malnutrition leads to kwashiorkor and marasmus. Liver mitochondrial and peroxisomal dysfunction - toxic microbial compounds produced in the gut such as ethanol, lipopolysaccharides and endotoxins and aflatoxin produced by Aspergillus species. Gut-liver axis alteration characterized by oedema and a fatty and enlarged 
liver is associated with a drastic depletion of methionine and glutathione, an excessive level of free circulating iron and frequent lethal bacteraemia by enteric pathogens. Only in children with kwashiorkor.

\subsection{Effect of Amoxicillin cellulitis infection}

Amoxicillin is administered for three days before the antibiotherapy to eradicate infectious cellulitis. Post blood culture and skin culture of an unroofed pustule, this dose of amoxicillin-clavulanic acid was halted. As the patient suffered from hypocalcemia, calcium was supplemented intravenously. In three days, the calcium level reached 1.3 $\mathrm{mmol} / \mathrm{L}$ from $0.9 \mathrm{mmol} / \mathrm{L}$ and on the thirteenth day reached $1.9 \mathrm{mmol} / \mathrm{L}$. And psoriasis improved without any other treatment. As per previous work also, Calciferol, Calcitriol and Cholecalciferol have a proven positive impact on treating psoriasis.For development or aggravation of psoriasis, calcium homeostasis could be responsible as hypocalcemia can damage cell adhesion(CAD) molecules (e.g., cadherins) as they are dependent on calcium.

Conclusions about psychiatric effects of Vitamin D are -

- HARMFUL EFFECT:

1. Vitamin D contributes to the prevalence and risk for developing Alzheimer disease by accentuating the clearance of amyloid-A peptides by heightening the expression of hemeoxygenase-1.
2. It influences the risk for developing schizophrenia. The lower levels of maternal vitamin D accentuates the risk of developing schizophrenia, particularly in the AfricanAmerican population.

- BENEFITS:

1. Vitamin D supplementation reinstates suppressed synaptic plasticity that is seen in Alzheimer Disease.

2. Protective role: attenuating the expression of the reduced form of nicotinamide adenine dinucleotide phosphate.

3. Vitamin D controls the expression of calcium sensing receptors and angiogenin, thus providing protection against development, progression of Alzheimer Disease.

\subsection{Intestinal Permeation enhancers}

Due to absorption enhancers like many intestinal permeation enhancers, it is very approachable for the pharma sector to invest and develop certain drugs without the fear of toxicity or insufficiency. The bioavailability of many drugs can be increased significantly.[2] Intestinal permeation enhancers are exepients which serve two purposes. Firstly, they increase the intestinal permeability of poorly absorbed drugs in the small intestine by opening the tight junctions, leading to the amplified paracellular permeability. Secondly, they improve the oral bioavailability. They must be reversible in their action and non-hazardous to Gastro-intestinal Tract epithelium.

Table 1: There are six main classes of intestinal permeation enhancers:

\begin{tabular}{|c|c|c|c|}
\hline $\begin{array}{l}\text { Sr. } \\
\text { No. }\end{array}$ & $\begin{array}{l}\text { Intestinal } \\
\text { permeation } \\
\text { enhancers }\end{array}$ & Mechanism of Intestinal permeability enhancers & Examples \\
\hline 1 & $\begin{array}{l}\text { Surfactants: Ionic and } \\
\text { Non-Ionic }\end{array}$ & $\begin{array}{l}\text { Disruption of intestinal epithelial cell membrane, drugs cross the } \\
\text { intestinal barrier through transcellular mechanism }\end{array}$ & $\begin{array}{lr}\text { Sodium } & \text { lauryl } \\
\text { sulphate } & \text { (SDS), } \\
\text { Tween80 } & \\
\end{array}$ \\
\hline 2 & $\begin{array}{l}\text { Bile salts \& their } \\
\text { derivatives }\end{array}$ & $\begin{array}{l}\text { Denaturation of proteins } \\
\text { Decrease of mucus viscosity } \\
\text { Decrease of peptidase activity } \\
\text { Solubilization of peptides } \\
\text { Formation of reversed micelles } \\
\text { Phospholipid acyl chain disruption }\end{array}$ & $\begin{array}{l}\text { Sodium } \\
\text { taurocholate, } \\
\text { Sodium } \\
\text { dihydrofusidate }\end{array}$ \\
\hline 3 & $\begin{array}{l}\text { Fatty acids \& their } \\
\text { derivatives }\end{array}$ & $\begin{array}{l}\text { By increasing intracellular calcium levels through the activation of } \\
\text { phospholipase } \mathrm{C} \text { in the plasma membrane. } \\
\text { This leads to induce the contraction of calmodulin-dependent actin } \\
\text { microfilaments/ peri-junctional actin-myosin ring, resulting in } \\
\text { increased paracellular permeability }\end{array}$ & $\begin{array}{l}\text { Sodium caprate, } \\
\text { Oleic acid }\end{array}$ \\
\hline 4 & Chelating agents & $\begin{array}{l}\text { form complexation of calcium and magnesium ions present in between } \\
\text { intestinal epithelial cells and thus, leads to opening of tight junctions }\end{array}$ & $\begin{array}{l}\text { EDTA, Citric } \\
\text { acid, Salicylates }\end{array}$ \\
\hline
\end{tabular}




\begin{tabular}{|l|l|l|l|}
\hline 5 & $\begin{array}{l}\text { Chitosans } \\
\text { derivatives }\end{array}$ & $\begin{array}{l}\text { polymers are able to tightly bind to the epithelium and induce } \\
\text { redistribution of cytoskeleton F-actin and the TJ protein ZO-1, } \\
\text { followed by enhanced transport via the paracellular pathway } \\
\text { act on tight junction and reduces its integrity and increases intestinal } \\
\text { permeability }\end{array}$ & $\begin{array}{l}\text { N-trimethylated } \\
\text { chloride(TMC), } \\
\text { Chitosan } \\
\text { glutamate }\end{array}$ \\
\hline 6 & $\begin{array}{l}\text { Other enhancers } \\
\text { Zonula occludens } \\
\text { toxin (Zot) and } \\
\text { polycarbophyl- } \\
\text { cysteine } \\
\text { conjugate(PCP-Cys) }\end{array}$ & $\begin{array}{l}\text { toxin interacts with a specific intestinal epithelial surface receptor, with } \\
\text { subsequent activation of a complex intracellular cascade of events able } \\
\text { to reversibly regulate tight junction permeability. } \\
\text { PCP-Cys exert their permeation enhancing effects via glutathione. It } \\
\text { transforms oxidized glutathione (GSSG) to reduced glutathione } \\
\text { (GSH), prolonging GSH concentration at the apical membrane. } \\
\text { GSH is capable of inhibiting protein tyrosine phosphatase (PTP) } \\
\text { leading to more phosphorylated occludin and to more open Tight } \\
\text { junction }\end{array}$ & $\begin{array}{l}\text { (Zot) } \\
\text { polycarbophyl- } \\
\text { cysteine } \\
\text { Cys) }\end{array}$ \\
\hline
\end{tabular}

\subsection{MDR}

MDR has created an emerging threat to global health and it makes the effective prevention and treatment of many, particularly severe infections challenging. Vitamin D possesses antimicrobial properties against both Grampositive and Gram-negative bacterial species, in invitro studies. An adjunct therapy in combination with antibiotic compounds and/or the antibiotic-independent application of vitamin D directed against infectious diseases such as tuberculosis, $H$. pylori infections, or skin diseases is a concern. In an Egyptian study, among 150 H. pylori-infected patients, the pathogen-eradicating capacity of vitamin $\mathrm{D}$ was assessed. Vitamin D levels were significantly higher in the successfully Helicobacter pylori eradicated cohort as compared to the fourteen-day triple therapy (including clarithromycin, amoxicillin, and omeperazole) nonresponders.

\subsection{COVID:}

In the pilot study, high doses of calcidiol or 25hydroxyvitamin D3 were administered. Confirmed results indicate that patients requiring hospitalization due to COVID 19 have significantly reduced the need for ICU treatment. The best treatment is to use hydroxychloroquine / Asian slobomycin therapy early on in your hospital. The new COVIDIOL trial based on information recently available as an interesting perspective is to evaluate the comparison of calcifediol with dexamethasone or other corticosteroids, since it has recently been shown that dextrose, which has a potent anti-inflammatory effect, can reduce the risk of Covid19. or accept respiratory mortality during hospitalization of assisted patients. A high degree of heterogeneity was observed between the use of repurposed drugs and the use of hydroxychloroquine, with large geographic and temporal differences. Azithromycin is a macrolide antibiotic that is said to have an antiviral effect on COVID-19, which is widely used. Recovery trials showed that azithromycin had no effect on hospitalized COVID19 patients. Over time, new tests continue to appear and the use of covid19 drugs can develop rapidly. Although it may not represent the global treatment model, the data provide good oversight for the treatment of hospitalized patients for COVID19 in the real world in 2020. The combination of ivermectin, azithromycin, and cholecalciferol can effectively eliminate non-pharyngeal transport of SARSCoV2 in patients affected by COVID 19. On the other hand, vitamin $\mathrm{D}$ can bind to viral spike glycoproteins, interfere with viral membrane-membrane fusion, aggravate lung damage, and reduce epithelial cell death. May allow activation to improve the clinic. Azithromycin acidifies the $\mathrm{pH}$, prevents the virus from fusing with endosomal membranes, reduces virus replication in the bronchial epithelium, and delays pulmonary fibrosis. The proposed mechanism of action of ivermectin, azithromycin and cholecalciferol on virus clearance and clinical improvement. These findings require further analysis to determine whether this combination is effective in severe cases. High-dose vitamin D supplementation in COPD patient samples did not reduce the incidence of exacerbations. For participants who are severely deficient in vitamin $D$ in the early stages, supplements may reduce the deterioration of the condition. The limitation of is that it is a single-center study with a small sample size. The published results of a randomized trial of vitamin $\mathrm{D}$ supplementation in patients with COPD indicate that the current vitamin $\mathrm{D}$ deficiency is derived from data from a recent randomized controlled trial conducted on healthy individuals. The current data are consistent with previous studies, showing that COPD $25(\mathrm{OH})$ D levels are not related to end-stage lung function decline or FEV1 response to inhaled corticosteroids. In summary, the baseline $25(\mathrm{OH}) \mathrm{D}$ level of patients with severe COPD cannot predict subsequent AECOPD. The results of recent drug treatment studies are beneficial, especially when considering new or alternative treatments for severe or difficult-to-control asthma. The authors found that there are many other alternatives underway and emphasized how to manage them. The proper balance of vitamin $\mathrm{B} 12$, vitamin $\mathrm{D}$, zinc, 
magnesium-containing vitamins, micronutrients, and minerals is essential for maintaining good health, and nutritional imbalance can cause many diseases. To reduce the burden of COVID19 on a global scale, it is better to maintain functional and nutritional status and improve immunity. More importantly, these improvements will lead to a balanced diet. The absence of serious side effects or complications also improves COVID19 safety. Although ivermectin exhibits different antiviral activities in vitro compared to nitazoxanide, the evidence for clinical antiviral activity is weak. The issue of the minimum concentration of ivermectin required for effective anti-SARSCoV2 action has been raised and has been reviewed in the RCT. Nitazoxanide was selected as a supplement to AndroCoVRCT, three drugs that performed well overall. However, it is recommended that all three drugs be tested in clinical trials because they may have a beneficial effect on COVID19 if they are diagnosed at least 344 to 7 days before the onset of symptoms. One limitation is that it is an unblinded trial that does not use a placebo as a control. Compared with a fully double-blind placebo-controlled RCT, the results are weaker. A detailed understanding of the potential risk factors for the biological effects of vitamin D can provide more information about the pathogenesis of the disease in Covid19 patients. , Including or excluding vitamin D status, including or excluding genetic polymorphism, skin type (pigmentation), age, sun exposure behavior, season, latitude, obesity, and nutrition, well-designed research considering that it is regulated by many internal and external Factors Factors including standards are important to better understand the exact role of vitamin D supplements in Covid19. The vitamin D level of 4,444 CF patients was lower than that of the control group, and even among the patients taking macrolides, it was also lower than the patients not taking.

\subsection{Inflammatory cytokines:}

Vitamin D was found to inhibit the production of inflammatory cytokines such as TNF $\alpha$, IL6, and IL8 in vivo and in vitro, and to increase the production of the antimicrobial peptide IL37 in CF airway epithelial cells. ZM for long-term treatment appears to improve the nutritional status of CF subjects, gain weight, and improve BMI. By reducing the dose and duration of azithromycin and targeting acute treatment, when the risk of treatment failure is higher, the benefits may outweigh the potential side effects of macrolides, which is a serious AE. It can lead to new treatment strategies. The antiviral activity of vitamin D has nothing to do with stimulating the innate immune response mediated through the IFN pathway. Inflammatory cytokine secretion in CF bronchial epithelial cells was found to be only slightly increased during RV infection. A clinical trial is needed to study the role of vitamin $\mathrm{D}$ in preventing $\mathrm{CF}$ virus-related lung deterioration. Lack of detailed smoking history, $25(\mathrm{OH})$ D levels, and duration of epidemic status may influence conclusions. Furthermore, the relatively small sample size may explain the lack of expression. A recent large-scale study analyzed gene expression data for key enzymes in lung tissue, including CYP24A1, CYP27B1, and VDR, partially confirming this finding.

\subsection{Respiratory tract infection and Covid-19}

Respiratory tract infections are associated with substantial morbidity and mortality. In World Health Report 2004, the World Health Organization estimated that respiratory tract infections had been the fourth predominant purpose of

mortality, responsible for four million deaths or $6.9 \%$ of the world quantity of deaths in 20026. Community-acquired pneumonia (CAP)

is a common and potentially serious illness that is related with morbidity and mortality. Although clinical care has accelerated throughout the previous decades, it is still doubtlessly lethal. Streptococcus pneumonia is the most conventional microorganism

Treatment includes mandatory antibiotic therapy and organ assist as needed. Nearly $80 \%$ of the cure for this situation is supplied in the outpatient setting. Treatment of CAP for the most section is empirical; therefore, any antibiotic treatment must cowl each standard and extraordin ary pathogens. The beta-lactams have traditionally been considered preferred therapy for the therapy of CAP. However, the impact of rising resistance fees is now a essential issue going through physicians. In one learn about it has been observed that in the management of community acquired pneumonia, monotherapy was once high quality in $70 \%$ of cases; the combination of two or greater antibiotics (cephalosporin + quinolones) was once required in $91.2 \%$ of patients. The aggregate of a fluoroquinolone and a $\beta$ - lactam, which are directed against distinct pursuits enhance efficacy in contrast with a fluoroquinolone by myself and might also decrease the risk of fluoroquinoloneresistant bacteria.. Given the fact that the outcomes of treatment of ALRIs managed in a tertiary care setting is excellent with negligible mortality, it is better that future studies focus more on preventive aspects of vitamin D administration in reducing morbidity and hospital admissions rather than on their therapeutic value in the acute management of infections in a tertiary care centre. The daily intake and amount of vitamin $\mathrm{D}$ required in the blood to support sustained AMP production against infectious microorganisms is currently unknown but is likely to be in the range of $10,000(250 \mathrm{mcg})$ IU/day to 25,000 (625 mcg) IU/day. The literature does not support hazards but instead significant advantages if the population could rapidly achieve and maintain robust serum $25(\mathrm{OH}) \mathrm{D}$ concentrations. It is known that the body generates $10,000(250 \mathrm{mcg}) \mathrm{IU} /$ day to $25,000(625 \mathrm{mcg}) \mathrm{IU} /$ day of vitamin $\mathrm{D}$ in the photosynthetic response to sunshine without causing hypercalcemia, while effectively treating tuberculosis infections, rickets and psoriasis plaques. Studies including our own extensive clinical experience over the past 11 years indicate these doses to be well-tolerated and safe, as well as inexpensive. Hence, we highly recommend that consideration be given for vitamin D supplementation in this 
range now to potentially protect people from the coronavirus. This is true for all populations but is especially true for African Americans, who are the most severely vitamin D deficient and who are suffering disproportionately worse outcomes from coronavirus infections. Current low-dose supplementation recommendations (600 (15 mcg) IU/day to $4000(100 \mathrm{mcg}) \mathrm{IU} /$ day $)$ appear to be insufficient to meet the goal of mounting a sustained protective host immune response including AMP production in the face of an overwhelming infection such as coronavirus. The risk to benefit ratio, low expense, and broad availability clearly favor the use of vitamin D in doses of at least 10,000 (250 $\mathrm{mcg}$ ) IU/day in adults during the deadly coronavirus pandemic that now confronts much of the world, while lower doses may be sufficient in younger people. Treatment with supra-recommended doses of vitamin D may save lives and prevent needless suffering, with very little downside risk. Hence, the potential benefits of this cost-effective intervention appear to clearly outweigh the risks. Our collective experience and analysis of the peer-reviewed vitamin.

\subsection{Effect of vitamin D supplements:}

Although this study was a post hoc analysis and statistically non-significant, this trial lends some support to the hypothesis that supplementation with 60,000 IU vitamin $\mathrm{D} / \mathrm{mo}$ is associated with lower risk of infection, particularly in older adults. The trial was registered at the Australian New Zealand Clinical Trials Registry (anzctr.org.au) as ACTRN12609001063202. The main conclusion of the research work was that Vitamin D3 supplementation of 1600 IE /day is safe to use in immune deficient patients with 25OHD levels less than $75 \mathrm{nmol} / \mathrm{L}$ and significantly reduced the antibiotic consumption in patients without immunoglobulin substitution.

\subsection{Antibacterial properties:}

The present study have dealt with the bacteriostatic activity of vitamin D forms ; D2 \&D3 and aimed to determine if this vitamin have the ability to inhibit bacterial growth or not also to detect which one (with certain concentration) have the high activity against clinical isolates.

\subsection{Effect of cefixime in the warfarin therapy:}

Warfarin is an oral anticoagulant and generally acts by way of depleting functional vitamin K-dependent protein factors-i.e., II, VII, IX, and X-used in blood clotting processes. These elements are formed precursory in the liver and activated with the aid of the carboxylation of precise glutamic acid residues, which also require nutrition $\mathrm{K}$ as a cofactor in its decreased form. Warfarin pastime is decided with the aid of the blood take a look at recognized as INR. The most latest guidelines published in 2017 provides indication of anticoagulation with a vitamin $\mathrm{K}$ antagonist (VKA) to reap an INR of 2.5 encouraged for sufferers with a mechanical bileaflet or current-generation single-tilting disc AVR with no threat elements for thromboembolism (class I
B). Anticoagulation with a VKA is indicated to obtain an INR of three in sufferers with a mechanical AVR and extra risk elements for thromboembolic activities (AF preceding thromboembo embolism) LV dysfunction, or hypercoagulable conditions) or an older-generation mechanical AVR (such as ball-in-cage). While, the 2014 recommendation remains contemporary (class I B). Anticoagulation with a VKA is indicated to attain an INR of 3 in sufferers with a mechanical MVR (class I B).

\subsection{Properties and therapeutic application:}

The study was done to find about the sources of Vitamin, the diseases that can occur due to its efficiency and it's deficiency also results in abnormalities in calcium, phosphorus, and bone metabolism. VDD causes a decrease in the absorption of dietary calcium and phosphorus, resulting in an increase in PTH levels, physiological actions of vitamin D. It also mentions about the disease that may occur like Hypertensions, Heart Diseases, Parkinson's Disease, Obesity, Fractures and Falls, Cognitive impairment, Influenza etc.

\subsection{Effect of synergistic strategy}

Easy penetration in the cells by small-size nanoparticle acts breaks DNA and proteins, resulting in cell lysis. They change the membrane permeability, and the cooperative action of nanoparticles and antibiotics breaks cell walls and membranes. These nanoparticles also hindered the activities of several antibiotics resistant proteins. The cell wall and nanoparticles interact due to opposite charges and augment its effects. Several scientific groups used $\mathrm{ZnO}$ nanoparticles and cephalosporins, beta-lactams, and aminoglycosides antibiotics to prove their antimicrobial effects against different pathogenic strains. A similar strategy was used in this study to notice the antimicrobial effect of $\mathrm{Zn} \mathrm{Nps.} \mathrm{The}$ antibiotics, along with nanoparticles both at less but effective concentrations, inhibit the growth of microbes. synthesized $\mathrm{ZnO}$ nanoparticles and studied their antimicrobial effects towards diverse pathogenic bacteria using the diffusion method. Obtained significant results with Salmonella typhi and pneumonia. Likewise, For Ni Nps also exhibited well antimicrobial activity against different bacteria and antifungicidal activity against Candida albicans. AgNPs improve the potency of most of the cefixime against MDR bacteria; therefore, this research provides helpful insight into typhoid treatment.

\section{CONCLUSION:}

This research review's purpose is to help the reader understand different aspects posed by the research on the therapeutic activity of vitamin $\mathrm{D}$ with antibiotics. This is significant because it gives insights about vitamin $\mathrm{D}$ with cefaroxune, Amoxicillin, cefixime, azithromycin. There has been much research and discussion conducted on these opinions of researcher and therapeutic activity of vitamin D with antibiotics. Most of the research found was on the vitamin D with cefaroxune, Amoxicillin, cefixime, azithromycin, lyme diseases, intestinal permeation, COVID, 
inflammatory cytokines, warfarin therapy. More research and testing is required to gain a better understanding of the therapeutic activity of vitamin D with antibiotics.

\section{ACKNOWLEDGEMENT:}

We would like to thank our supervisor/guide Bharat Kwatra, from Invenzion Labs Inc. whose expertise was invaluable in formulating the research questions, methodology and drawing conclusions. His insightful feedback and guidance pushed us to sharpen our thinking and brought our work to a higher level.

\section{ETHICS APPROVAL AND CONSENT TO PARTICIPATE. \\ Not applicable.}

\section{HUMAN AND ANIMAL RIGHTS}

No Animals/Humans were used for studies that are base of this research.

\section{CONSENT FOR PUBLICATION}

Not applicable.

\section{OAVAILABILITY OF DATA AND MATERIALS}

The author confirms that the data supporting the findings of this research are available within the article.

\section{FUNDING ACKNOWLEDGEMENT AND CONFLICT OF INTEREST}

The authors whose names are listed immediately above certify that they have NO affiliations with or involvement in any organization or entity with any financial interest (such as honoraria; educational grants; participation in speakers' bureaus; membership, employment, consultancies, stock ownership, or other equity interest; and expert testimony or patent-licensing arrangements), or non-financial interest (such as personal or professional relationships, affiliations, knowledge or beliefs) in the subject matter or materials discussed in this manuscript.

\section{REFERENCES.}

1. Agha, A., Asiri, H., Shehri, A., Bella, A. \& Bazeed, M. A case of relapsing polychondritis mimicking Ludwig's angina. Rheumatol. Reports, (2009).

2. Anilkumar, P. et al. a Rationalized Description on Study of Intestinal Barrier, Drug Permeability and Permeation Enhancers. J. Glob. Trends Pharm. Sci.(2011).

3. Akter, M. R., Akanda, K. M., Islam, S. \& Rana, M. Assessment of drug utilization pattern among outpatients in the orthopedic department of several private clinics in Rajshahi city, Bangladesh Assessment of drug utilization pattern among outpatients in the orthopedic department of several private clinics. (2020).

4. Apr, O. Vitamin b12 and Metformin drug interactions a phase IV clinical study of FDA data Summary. (2021).

5. Basta-Juzbašić, A. et al. A dose-finding study of azithromycin in the treatment of acne vulgaris. Acta
Dermatovenerologica Croat. (2007).

6. Brown, S. M. et al. Hydroxychloroquine versus azithromycin for hospitalized patients with suspected or confirmed COVID-19 (HAHPS) protocol for a pragmatic, open-label, active comparator trial. Ann. Am. Thorac. Soc. (2020).

7. Cadegiani, F., Goren, A., McCoy, J. \& Wambier, C. Hydroxychloroquine, nitazoxanide and ivermectin have similar effects in early COVID-19: a head-to-head comparison of the Pre-AndroCoV Trial. ResearchSquare (2020).

8. Carlberg, C. \& Molnar, F. Current Status of Vitamin D Signaling and Its Therapeutic Applications. Curr. Top. Med. Chem.(2012).

9. Crossley, V. J., Bovens, C. P., Pineda, C., Hibbert, A. \& Finch, N. C. Vitamin D toxicity of dietary origin in cats fed a natural complementary kitten food. J. Feline Med. Surg. Open Reports , 205511691774361 (2017).

10. Ding, Q. et al. Effect of zoledronic acid on lumbar spinal fusion in osteoporotic patients. Eur. Spine J. (2017).

11. Disease, O. P. Original Research Obstructive Pulmonary Disease. Ann. Intern. Med. (2012).

12. Entrenas, M., Manuel, L., Costa, E., Bouillon, R. \& Francisco, J. Since January 2020 Elsevier has created a COVID-19 resource centre with free information in English and Mandarin on the novel coronavirus COVID- 19 . The COVID-19 resource centre is hosted on Elsevier Connect the company' s public news and information . (2020).

13. Espitia-Hernandez, G., Munguia, L., Diaz-Chiguer, D., Lopez-Elizalde, R. \& Jimenez-Ponce, F. Effects of Ivermectin-azithromycin-cholecalciferol combined therapy on COVID-19 infected patients: A proof of concept study. Biomed. Res. (2020).

14. Faculty, I. M. et al. Ibrahim Adak, MD Ismail Akaltun, MD. Influence of Vitamin D Consumption and Levels on the Development of Psychiatric Disorders. (2014).

15. Golpour, A., Bereswill, S. \& Heimesaat, M. M. Antimicrobial and immune-modulatory effects of vitamin D provide promising antibiotics-independent approaches to tackle bacterial infections - lessons learnt from a literature survey. Eur. J. Microbiol. Immunol.(2019).

16. Guo, C. \& Gombart, A. The Antibiotic Effects of Vitamin D. Endocrine, Metab. Immune Disord. Targets. (2014).

17. Han, C. et al. Influence of serum vitamin D level on Helicobacter pylori eradication: A multi-center, observational, prospective and cohort study. J. Dig. Dis. (2019).

18. Huang, B., Yan, S., Chen, C. \& Ye, S. Effect of 25hydroxyvitamin $\mathrm{D}$ on Helicobacter pylori eradication in patients with type 2 diabetes. Wien. Klin. Wochenschr (2019).

19. Hu, Y., Zhu, Y., Lu, N. H. \& Shi, Q. Recent progress in Helicobacter pylori treatment. Chin. Med. J. (Engl). (2020).

20. Kapadia, C. et al. Nanoparticles combined with cefixime 
as an effective synergistic strategy against Salmonella enterica typhi. Saudi J. Biol. Sci. (2021).

21. Khelkal, I. N. Comparison the Antibacterial Activity of Vitamin D2 and D3. Al-Mustansiriyah J. Sci. (2017).

22. Kubota, Y. et al. Small intestinal bacterial overgrowth as a cause of protracted wound healing and vitamin D deficiency in a spinal cord injured patient with a sacral pressure sore: A case report. BMC Gastroenterol, (2020).

23. Kunisaki, K. M., Niewoehner, D. E. \& Connett, J. E. Vitamin D levels and risk of acute exacerbations of chronic obstructive pulmonary disease: A prospective cohort study. Am. J. Respir. Crit. Care Med. (2012).

24. Kushner, M. Effects of Food on Behavior. JAMA J. Am. Med. Assoc. (1984).

25. Laviano, E. et al. Association between preoperative levels of 25-hydroxyvitamin D and hospital-acquired infections after hepatobiliary surgery: A prospective study in a third-level hospital. PLoS One,(2020).

26. Liaqat, A., Khan, A. U., Asad, M. \& Khalil, H. Effect of quinolones versus cefixime on international normalized ratio levels after valve replacement surgery with warfarin therapy. Med. (2019).

27. Linday, L. A., Dolitsky, J. N. \& Shindledecker, R. D. Nutritional supplements as adjunctive therapy for children with chronic/recurrent sinusitis: Pilot research. Int. J. Pediatr. Otorhinolaryngol, (2004).

28. Islek, I., Gok, F., Albayrak, D. \& Kucukoduk, S. Nephrotic syndrome following cefixime therapy in a 10month-old girl: Spontaneous resolution without corticosteroid treatment. Nephrology Dialysis Transplantation vol. (1999).

29. Jungreis, I. \& Kellis, M. Mathematical analysis of Córdoba calcifediol trial suggests strong role for Vitamin D in reducing ICU admissions of hospitalized COVID-19 patients. medRxiv 2020.11.08.20222638 (2020).

30. Natividad-Pedreño, M. et al. Effect of cefazolin and cefuroxime on fracture healing in rats. Injury, (2016).

31. Masson, L. et al. A pustular psoriasis flare treated with calcium supplementation. JAAD Case Reports,(2021)

32. Mathyssen, C. et al. Local expression profiles of vitamin D-related genes in airways of COPD patients. Respir. Res. (2020).

33. Mccullough, P. J. et al. The Essential Role of Vitamin D in the Biosynthesis of Endogenous Antimicrobial Peptides May Explain Why Deficiency Increases Mortality Risk in COVID-19 Infections. Preprints.org (2020).

34. Mufti, A. et al. Treatment outcomes in confluent and reticulated papillomatosis: A systematic review. J. Am. Acad. Dermatol. (2021).

35. Norlin, A. C. et al. Vitamin D3 supplementation and antibiotic consumption Results from a prospective, observational study at an immune-deficiency unit in Sweden. PLoS One. (2016).

36. Olveira, C. et al. Kistik fibrozisi olan hastalarda enflamasyon ve oksidasyon biyobelirteçleri:
Azitromisinin etkisi. Eurasian J. Med. (2017).

37. Pham, T. P. T., Alou, M. T., Golden, M. H., Million, M. \& Raoult, D. Difference between kwashiorkor and marasmus: Comparative meta-analysis of pathogenic characteristics and implications for treatment. Microb. Pathog., 104702 (2021).

38. Prats-Uribe, A. et al. Use of repurposed and adjuvant drugs in hospital patients with covid-19: Multinational network cohort study. BMJ , (2021).

39. Razzaque, M. COVID-19 pandemic: Can boosting immune responses by maintaining adequate nutritional balance reduce viral insults? Adv. Hum. Biol. (2020).

40. Schögler, A. et al. Vitamin D represses rhinovirus replication in cystic fibrosis cells by inducing LL-37. Eur. Respir. J. (2016).

41. Shafrir, A. et al. The association between serum vitamin $\mathrm{d}$ levels and helicobacter pylori presence and eradication. Nutrients, (2021).

42. Slow, S. et al. Effect of adjunctive single high-dose vitamin D3 on outcome of community-acquired pneumonia in hospitalised adults: The VIDCAPS randomised controlled trial. Sci. Rep. (2018).

43. Somnath, S. H., Biswal, N., Chandrasekaran, V., Jagadisan, B. \& Bobby, Z. Therapeutic effect of vitamin $\mathrm{D}$ in acute lower respiratory infection: A randomized controlled trial. Clin. Nutr. ESPEN. (2017).

44. $\mathrm{Su}, \mathrm{D}$. et al. Vitamin D signaling through induction of paneth cell defensins maintains gut microbiota and improves metabolic disorders and hepatic steatosis in animal models. Front. Physiol. (2016).

45. Teymoori-Rad, M. \& Marashi, S. M. Vitamin D and Covid-19: From potential therapeutic effects to unanswered questions. Rev. Med. Virol. (2021).

46. T Donta, S. Issues in the Diagnosis and Treatment of Lyme Disease. Open Neurol. J. (2012).

47. Tomar, L., Govil, G. \& Dhawan, P. Bilateral Femoral Neck Stress Fracture in an Obese Middle-Aged Female With Osteomalacia and Coxa-Vara Managed by Simultaneous Bilateral Total Hip Arthroplasty. Cureus, (2020).

48. Tran, B. et al. Effect of vitamin D supplementation on antibiotic use: A randomized controlled trial. Am. J. Clin. Nutr. (2014).

49. Trenk, D., Wagner, F., Bechtold, H., Nies, B. \& Jahnchen, E. Lack of effect of cefixime on the metabolism of vitamin K1. J. Clin. Pharmacol. (1990).

50. Vermeersch, $K$. et al. The Belgian trial with azithromycin for acute COPD exacerbations requiring hospitalization: An investigator-initiated study protocol for a multicenter, randomized, double-blind, placebocontrolled trial. Int. J. COPD. (2016).

51. Vrancken, L. et al. What is new in the management of multiple myeloma. Rev. Med. Suisse (2018).

52. Youssef, D. A. et al. Antimicrobial implications of vitamin D. Dermato-Endocrinology vol. 3 (2011).

53. Zittermann, A. et al. Circulating 25-hydroxyvitamin D and 1,25-Dihydroxyvitamin D concentrations and postoperative infections in cardiac surgical patients: The 
CALCITOP-study. PLoS One , (2016).

54. Zhang, Q., Liu, F., Zeng, M., Mao, Y. \& Song, Z. Drug 55. repurposing strategies in the development of potential antifungal agents. Appl. Microbiol. Biotechnol (2021). 